\title{
Asymmetric Hydroformylation of Heterocyclic Olefins Mediated by Supramolecularly Regulated Rhodium-Bisphosphite Complexes
}

\author{
Laura Rovira $^{\dagger}$, Mónica Vaquero ${ }^{\dagger}$ and Anton Vidal-Ferran ${ }^{\dagger \ddagger^{*}}$ \\ ${ }^{\dagger}$ Institute of Chemical Research of Catalonia (ICIQ), Avgda. Països Catalans 16, 43007 Tarragona, Spain. Phone +34 \\ 977920210, Fax + 34977920228. \\ ${ }^{\ddagger}$ Catalan Institution for Research and Advanced Studies (ICREA), Passeig Lluís Companys 23, o8o1o Barcelona, \\ Spain.
}

\section{Supporting Information}

\begin{abstract}
Rhodium complexes derived from conformationally transformable $\alpha, \omega$-bisphosphite ligands combined with a suitable alkali metal BArF salt as a regulation agent (RA) provide high regio- and enantioselectivities in the asymmetric hydroformylation (AHF) of three heterocyclic olefins. The outcome of the AHF could be exquisitely regulated by choosing the appropriate RA with an increase in the ee, the reversal of the regioselectivity, or the complete suppression of one byproduct.
\end{abstract}

The development of efficient strategies for generating libraries of enantioselective catalysts with minimal synthetic efforts remains an appealing challenge. Supramolecular interactions have been used to regulate the size, shape and first coordination sphere of a chiral catalyst. ${ }^{1}$ However, there are few examples of the fine modification of the geometry of the active site. ${ }^{2,3}$ Our group has developed supramolecularly regulated bisphosphite ligands possessing two different structural features: a catalytic site consisting of two identical phosphite fragments and a distal regulation site containing a polyether chain. Ion-dipole interactions between the polyether chain and the regulation agent (RA; e.g. alkali metal salts; see Scheme 1) bring the ligating groups together at the metal center. ${ }^{2}$ Furthermore, the library of catalysts arising upon the binding of an array of RAs to the regulation site not only preserves most of the structural characteristics but also incorporates structural peculiarities that depend on the size and shape of the RA employed. Hydroformylation is an attractive industrial process requiring transition metal catalysts, ${ }^{4}$ from which rhodium complexes derived from bisphosphite ligands have been used with variable success in the hydroformylation of heterocyclic alkenes. ${ }^{5}$ Herein, we describe the design and synthesis of new supramolecularly regulated ligands $(R, S)$-L2 and $(S, S)$ - $\mathbf{L} \mathbf{3}$ (Scheme 1), which incorporate a [1,1'-binaphthalene]-2,2'-diol motif in the regulation site. We also show that the inclusion of this motif reinforces the regulation ability of the catalysts and leads to efficient AHF catalysts for a number of heterocyclic olefins.

The new ligands, $(R, S)$ - $\mathbf{L} \mathbf{2}$ and $(S, S)$-L $\mathbf{3}$, were synthesized by O-phosphorylation ${ }^{6}$ of the corresponding diol derivatives. Ligand (S)-L1, which lacks a stereogenic element in the regulation site, was also considered in order to aid comparison and was synthesized in an analogous manner (see the Experimental Section).

We first tested the activity of these new ligands in the AHF of benchmark substrates comprising vinyl esters 1a-c, styrene $\mathbf{1 d}$ and (allyloxy)trimethylsilane 1e (Scheme 2 and Table 1). Initial studies were performed with $\left[\mathrm{Rh}\left(\kappa^{2} \mathrm{O}, \mathrm{O}^{\prime}-\right.\right.$ acac) $(\mathrm{CO})_{2}$ ] and the corresponding ligand at $40{ }^{\circ} \mathrm{C}$ under 10 bar syngas in toluene, with the minimum amount of THF to solubilize the RA. ${ }^{2 a, c}$ The results on AHF are partially summarized in Table 1, which summarizes the results for the catalysts that show the highest positive regulation effects. ${ }^{7}$ In the case of vinyl ester derivatives $\mathbf{1 a - c}$, the reactions performed in the absence of RAs yielded aldehydes with lower conversions than those in which an RA was used. Rhodium complexes derived from ligands $(S)$-L1 and $(R, S)$ - $\mathbf{L} 2$ provided highly active catalysts and remarkable enhancements in the enantioselectivity of the hydroformylation of 1a-c (with increases ranging from 69 to $77 \%$ ee; see entries 1-6 in Table 1). The combined use of $(S, S)-\mathbf{L}_{\mathbf{3}}$ and NaBArF provided the highest enantioselectivity for styrene $(\mathrm{b} / \mathrm{l}$ ratio $=96: 4 ; 54 \%$ ee; see entry 8 in Table 1), whereas the highest enantioselectivities were achieved for compound 1e with $(S, S)$-L $\mathbf{3}$ and CsBArF (b/l ratio $=18: 82 ; 23 \%$ ee; see entry 10 in Table 1$)$. The principal steric directors in our catalysts are the bisphosphite units, which favor the formation of $(R)$-configured products, although the configuration of the [1,1'-binaphthalene]-2,2'diol motif is also decisive in obtaining the highest performing ligands.

After testing the AHF of linear substrates with our catalysts, we moved on to the AHF of heterocyclic olefins, given the applicability of enantiopure heterocyclic aldehydes in the 
synthesis of biologically relevant products. $^{8}$ Our group ${ }^{9}$ and others have studied the AHF of five-,,$^{5 \mathrm{~b}, 8 \mathrm{a}, 10}$ six-, ${ }^{100}$ and seven-
${ }^{5 b, 10 a, c}$ membered heterocyclic olefins and reported problems in the control of chemo- and regioselectivity.
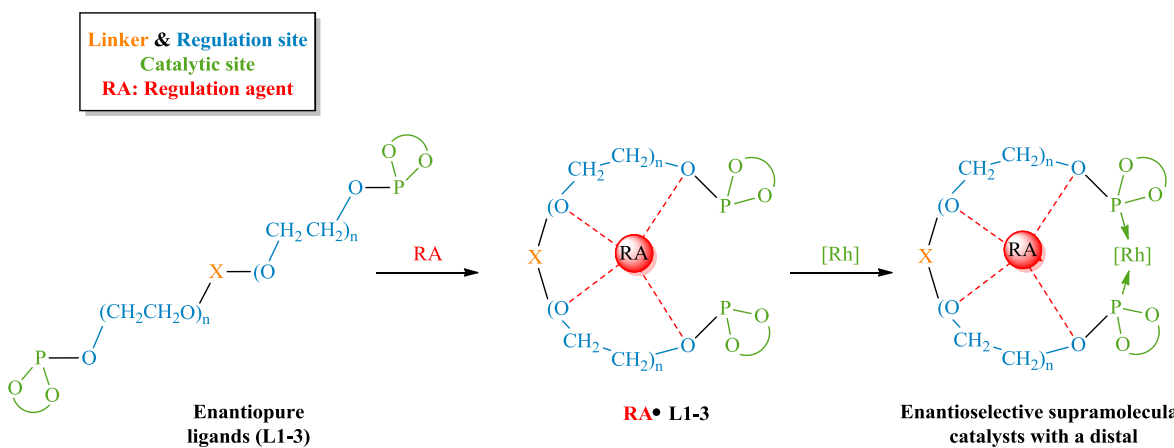

Enantiopure

RA・ L1-3

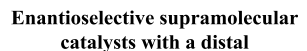

egulation site [Rh(RA a 1-3)]

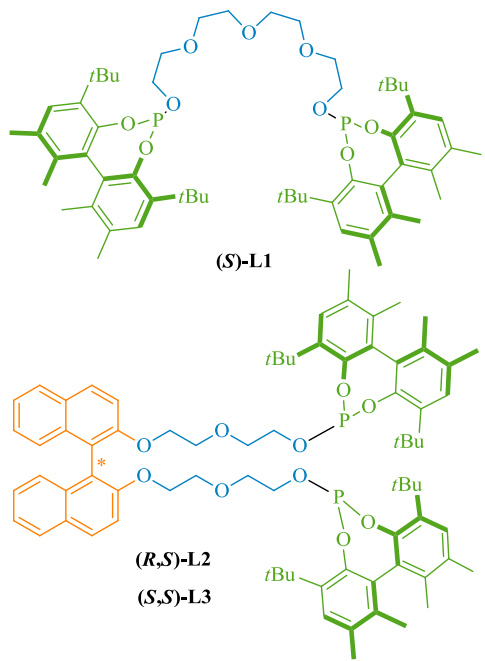

Scheme 1. Supramolecularly regulated bisphosphite ligands with a distal regulation site.

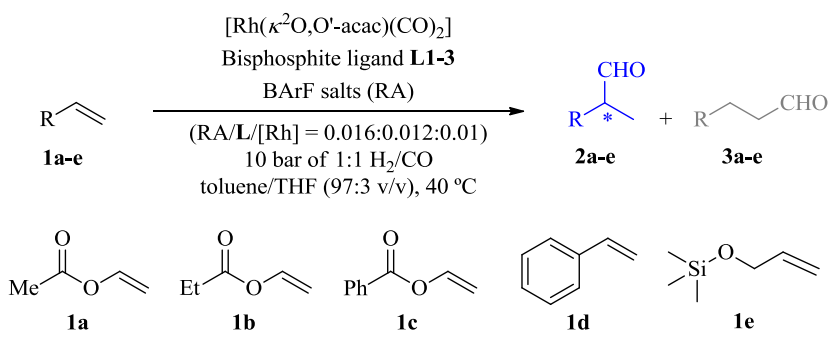

Scheme 2. AHF of compounds ra-e mediated by supramolecularly regulated ligands $\mathbf{L}-\mathbf{3}$.

In the AHF of 2,5-dihydrofuran, the expected tetrahydrofuran-3-carbaldehyde (6), the regioisomeric aldehyde 5 and 2,3dihydrofuran (7) can be formed (Scheme 3 and Table 2). The latter compound arises from a $\mathrm{C}=\mathrm{C}$ bond isomerization that occurs simultaneously with the hydroformylation."

Supramolecularly regulated ligands L1-3 proved to be very active in the AHF of 2,5-dihydrofuran (with conversions ranging from 92 to $>99 \%$; Table 2 ). In the reactions performed without an RA, carbaldehyde 6 was obtained as the major product, although in poor enantioselectivities (from 36 to $38 \%$ ee; Table 2 ), together with small amounts of isomerization product 7 (from 5 to 9\%; see entries 1,6 and 11 in Table $2)$. The combined use of $(R, S)-\mathbf{L} 2$ with $\mathrm{KBArF}$ as the RA had several major effects in the outcome of the reaction. First, the use of ligand $(R, S)$-L2 and KBArF brought about a reversal of regioselectivity in favor of tetrahydrofuran-2-carbaldehyde (5/6 ratio from 1:92 to 35:39; compare entries 6 and 8 in Table 2); second, they induced a change in the configuration of the final product and an increase in the ee (from $11 \%$ ee in favor of $(S)-5$ to $82 \%$ ee in favor of $(R)_{-5}$; compare entries 6 and 8 in Table 2). It is interesting that the reversal of regioselectivity was associated with major amounts of isomerization product 7 (from 7 to 26\%; compare entries 6 and 8 in Table 2 ).

To gain more information about this complex transformation, the hydroformylation of 2,3-dihydrofuran under the same conditions was also studied (see Scheme 3 and Table 3 ).
Substrate 7 reacted more slowly than compound 4 under the same reaction conditions, with or without an RA (conversion from 7 to $89 \%$; Table 3 ). The use of an RA increased activity in almost all the examples tested. The major product of the hydroformylation of 7 was tetrahydrofuran-2-carbaldehyde (5) in moderate to high enantioselectivities (e.g., $(R, S)$-L2 and $\mathrm{KBArF}$ led to $81 \%$ ee in favor of $(R)-5$; entry 8 in Table 3 ).

Table 1. AHF of 1a-e using the catalysts that lead to the highest regulation effects ${ }^{\mathrm{a}}$

\begin{tabular}{|c|c|c|c|c|c|c|}
\hline entry & ligand & substrate & RA & $\begin{array}{l}\text { conv } \\
(\%)\end{array}$ & $\begin{array}{c}\mathrm{b} / \mathrm{l} \\
\text { ratio }\end{array}$ & $\begin{array}{c}\text { ee of } 2 \\
(\%) \\
\text { config. }\end{array}$ \\
\hline 1 & \multirow{2}{*}{$\begin{array}{c}(R, S)- \\
\mathbf{L 2}\end{array}$} & \multirow{2}{*}{$1 \mathbf{a}$} & - & 92 & $>99: 1$ & $23(R)$ \\
\hline 2 & & & RbBArF & $>99$ & $>99: 1$ & $92(R)$ \\
\hline 3 & \multirow{2}{*}{$\begin{array}{c}(R, S)- \\
\text { L2 }\end{array}$} & \multirow{2}{*}{$\mathbf{l b}$} & - & 94 & $>99: 1$ & $15(R)$ \\
\hline 4 & & & $\mathrm{KBArF}$ & $>99$ & $>99: 1$ & $92(R)$ \\
\hline 5 & \multirow{2}{*}{$(S)-\mathbf{L} \mathbf{1}$} & \multirow{2}{*}{ 1C } & - & 90 & $>99: 1$ & $7(S)$ \\
\hline 6 & & & $\mathrm{NaBArF}$ & 78 & $98: 2$ & $76(R)$ \\
\hline 7 & \multirow{2}{*}{$\begin{array}{c}(S, S)- \\
\mathbf{L}_{3}\end{array}$} & \multirow{2}{*}{ Id } & - & $>99$ & $95: 5$ & $42(R)$ \\
\hline 8 & & & $\mathrm{NaBArF}$ & $>99$ & $96: 4$ & $54(R)$ \\
\hline 9 & \multirow{2}{*}{$\begin{array}{c}(S, S)- \\
\mathbf{L}_{3}\end{array}$} & \multirow[b]{2}{*}{ 1e } & - & $>99^{b}$ & $61: 39^{b}$ & $17(R)$ \\
\hline 10 & & & CsBArF & $>99^{\mathrm{b}}$ & $18: 82^{b}$ & $23(R)$ \\
\hline
\end{tabular}

${ }^{\mathrm{a}}$ Reaction conditions are shown in Scheme 2. Conversion was determined by GC chromatography ( $\beta$-Dex 225) using $n$-dodecane as internal standard unless otherwise stated. The ratio of the regioisomers and ee values were determined by GC analysis on a chiral stationary phase ( $\beta$-Dex 225) unless otherwise stated. Absolute configurations were assigned by comparing the elution order in GC analysis with reported data (for details, see Experimental Section). ${ }^{\text {b }}$ Conversion and regioselectivity were determined by ${ }^{1} \mathrm{H}$ NMR.

To minimize the formation of isomerization product 7 and enhance regioselectivity toward carbaldehyde $\mathbf{5}$, we decided to study the effect of variable amounts of $\mathrm{H}_{2}$ and $\mathrm{CO}$ in the syngas mixture on the outcome of the AHF of 4 . We also hoped to be able to identify the AHF conditions that lead to carbaldehyde 5 being the most abundant product. These 
studies were performed with ligand $(R, S)$-L2 and KBArF, as their combined use provided the best results in terms of enantioselectivity for product 5 (see entry 8 in Table 2 ).

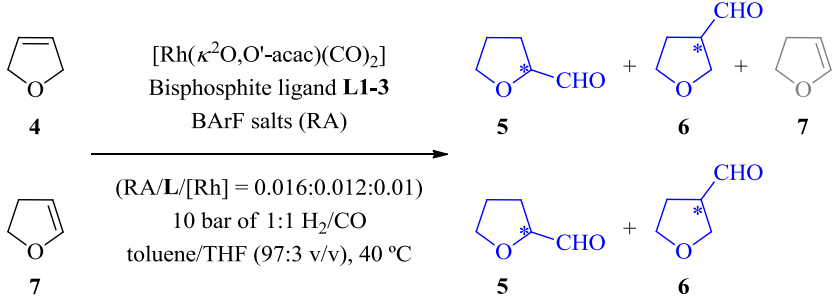

Scheme 3. AHF of 4 and 7 mediated by supramolecularly regulated ligands $\mathbf{L}-\mathbf{3}$.

Table 2. AHF of 4 using Rh-complexes of ligands L1-3 and a set of BArF salts as RAs. ${ }^{\text {a }}$

\begin{tabular}{ccccccc}
\hline entry & ligand & RA & $\begin{array}{c}\text { conv. } \\
(\%)\end{array}$ & $\begin{array}{c}\text { ratio } \\
\mathbf{5}: 6: 7\end{array}$ & $\begin{array}{c}\text { ee of } \mathbf{5} \\
(\%) \\
\text { config. }\end{array}$ & $\begin{array}{c}\text { ee of } \mathbf{6} \\
(\%) \\
\text { config. }\end{array}$ \\
\hline 1 & & - & $>99$ & $\mathbf{2 : 9 3 : 5}$ & $23(S)$ & $38(R)$ \\
2 & & NaBArF & 92 & $5: 73: 22$ & $60(R)$ & $61(S)$ \\
3 & $(S)$-L1 & KBArF & $>99$ & $21: 15: 64$ & $74(R)$ & $60(S)$ \\
4 & & RbBArF & $>99$ & $25: 31: 44$ & $77(R)$ & $21(S)$ \\
5 & & CsBArF & $>99$ & $13: 72: 15$ & $52(R)$ & $15(R)$ \\
\hline 6 & & - & $>99$ & $1: 92: 7$ & $11(S)$ & $36(R)$ \\
7 & & NaBArF & 98 & $1: 91: 8$ & $2(S)$ & $25(R)$ \\
8 & $(R, S)-$ & KBArF & $>99$ & $35: 39: 26$ & $82(R)$ & $56(S)$ \\
9 & L2 & RbBArF & $>99$ & $34: 26: 40$ & $81(R)$ & $52(S)$ \\
10 & & CsBArF & $>99$ & $19: 38: 43$ & $76(R)$ & $14(S)$ \\
\hline 11 & & - & 98 & $1: 90: 9$ & $10(S)$ & $38(R)$ \\
12 & & NaBArF & $>99$ & $1: 97: 2$ & $34(S)$ & $42(R)$ \\
13 & $(S, S)-$ & KBArF & 96 & $3: 85: 12$ & $18(R)$ & $2(S)$ \\
14 & L3 & RbBArF & 93 & $4: 69: 27$ & $45(R)$ & $13(S)$ \\
15 & & CsBArF & 97 & $5: 70: 25$ & $43(R)$ & $18(R)$ \\
\hline
\end{tabular}

${ }^{\mathrm{a}}$ See footnote a in Table 1 for details, with the following remarks: Reaction conditions are shown in Scheme 3, and the amount of 7 was determined by ${ }^{1} \mathrm{H}$ NMR.

The AHF of 4 at 10 bar employing a 1:1 $\mathrm{H}_{2} / \mathrm{CO}$ mixture led to $\mathbf{5}$ in a selectivity of $35 \%$ with $82 \%$ ee, together with the formation of 7 with a selectivity of $26 \%$. Independently of the total pressure employed in the AHF, increasing the amount of $\mathrm{H}_{2}$ with respect to $\mathrm{CO}$ led to an increase in selectivity toward 5 and a reduction in the amount of isomerization product 7 (see Table S6 and Figure S1 in the Supporting Information). ${ }^{12}$ One of the most attractive AHF conditions was obtained at 5 bar with a $4: 1 \mathrm{H}_{2} / \mathrm{CO}$ mixture, under which 7 was not detected and carbaldehyde $\mathbf{5}$ was formed with a selectivity of $71 \%$ with $69 \%$ ee (Figure 1 ).

Ligands L1-3 were also tested in the AHF of six-membered heterocyclic olefins (see Supporting Information for the substrates studied and results obtained). Unfortunately our catalysts were not active in the AHF of these types of compounds. It has already been reported in the literature that these substrates normally require harsh reaction conditions in AHF, which reduce control of regio- and enantioselectivity.

Table 3. AHF of 7 using Rh-complexes of ligands L1-3 and a set of BArF salts as RAs. ${ }^{\text {a }}$

\begin{tabular}{ccccccc}
\hline entry & ligand & RA & $\begin{array}{c}\text { conv. } \\
(\%)\end{array}$ & $\begin{array}{c}\text { ratio } \\
\mathbf{5}: 6: 7\end{array}$ & $\begin{array}{c}\text { ee of } \mathbf{5} \\
(\%) \\
\text { config. }\end{array}$ & $\begin{array}{c}\text { ee of } \mathbf{6} \\
(\%) \\
\text { config. }\end{array}$ \\
\hline 1 & & - & 7 & $2: 5: 93$ & $5(S)$ & $26(S)$ \\
2 & & NaBArF & 31 & $18: 13: 69$ & $62(R)$ & $44(R)$ \\
3 & $(S)$-L1 & KBArF & 23 & $21: 2: 77$ & $76(R)$ & $8(S)$ \\
4 & & RbBArF & 39 & $34: 5: 61$ & $79(R)$ & $2(S)$ \\
5 & & CsBArF & 89 & $57: 32: 11$ & $56(R)$ & $6(S)$ \\
\hline 6 & & - & 32 & $12: 20: 68$ & $13(S)$ & $16(S)$ \\
7 & & NaBArF & 40 & $17: 23: 60$ & $3(S)$ & $8(R)$ \\
8 & $(R, S)-$ & KBArF & 65 & $52: 13: 35$ & $81(R)$ & $20(R)$ \\
9 & L2 & RbBArF & 57 & $48: 9: 43$ & $79(R)$ & $10(R)$ \\
10 & & CsBArF & 40 & $33: 7: 60$ & $75(R)$ & rac \\
\hline 11 & & - & 29 & $10: 19: 71$ & $11(S)$ & $14(S)$ \\
12 & & NaBArF & 31 & $11: 20: 69$ & $24(S)$ & $15(S)$ \\
13 & $(S, S)-$ & KBArF & 50 & $30: 20: 50$ & $19(R)$ & rac \\
14 & L3 & RbBArF & 32 & $22: 10: 68$ & $44(R)$ & $13(S)$ \\
15 & & CsBArF & 28 & $19: 9: 73$ & $44(R)$ & $16(S)$ \\
\hline
\end{tabular}

${ }^{\mathrm{a}}$ See footnote a in Table $\mathbf{1}$ for details, with the following remarks: Reaction conditions are shown in Scheme 3 and the amount of $\mathbf{7}$ was determined by ${ }^{1} \mathrm{H}$ NMR.

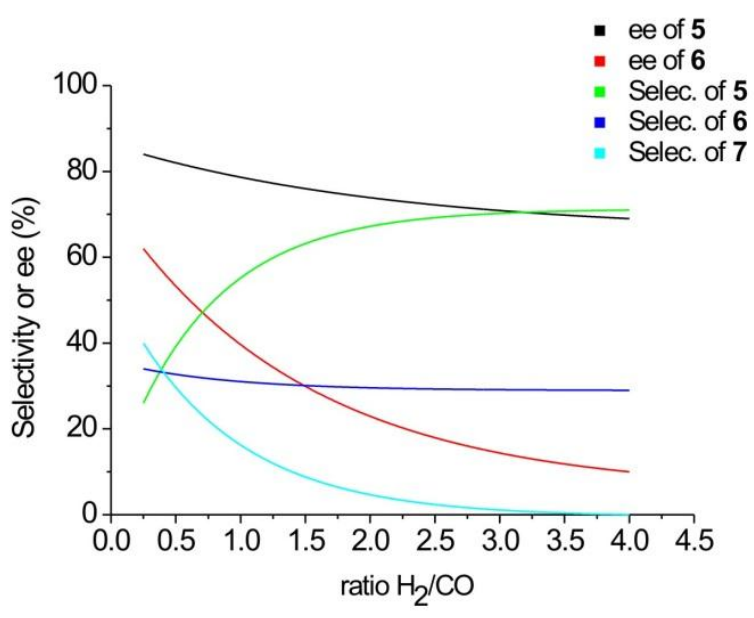

Figure 1. AHF of 4 at 5 bar with different syngas mixtures.

Finally, ligands $(S)$-L1, $(R, S)$ - $\mathbf{L} 2$ and $(S, S)$-L3 were tested in the AHF of cis-4,7-dihydro-1,3-dioxepin (8) with a set of alkali BArF salts as RAs (see Scheme 4 and Table 4 ).

The reactions showed complete regioselectivity toward product 9 (see Table 4 and S8). The use of RAs led to a great improvement in the conversion (up to $82 \%$ ) and enantioselectivity (up to 79\%). The highest enantioselectivities were obtained with combinations $(S)-\mathbf{L 1} / \mathrm{NaBArF}(85 \%$ ee), $(R, S)$ - 
L2/KBArF ( $83 \%$ ee), and $(S, S)$-L3/RbBArF (74\% ee) (entries 2, 5 , and 8 , respectively, in Table 4$)$. In order to increase the enantioselectivity, these reactions were performed at room temperature (entries 3, 6, and 9 in Table 4). Improvements ranging from 7 to $15 \%$ in the ee were observed, with the combination $(R, S)-\mathbf{L} \mathbf{2} / \mathrm{KBArF}$ being the best for this transformation. Carbaldehyde 9 was obtained with an excellent enantioselectivity ( $93 \%$ ee), which, to the best of our knowledge, is the highest reported for this substrate. ${ }^{\text {10a }}$

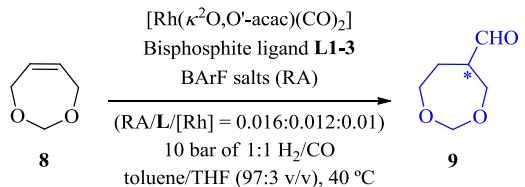

Scheme 4. AHF of $\mathbf{8}$ mediated by supramolecularly regulated ligands L1-3.

Table 4. AHF of 8 using Rh-complexes of ligands L1-3 and a set of BArF salts as RAs. ${ }^{\text {a }}$

\begin{tabular}{ccccc}
\hline entry & ligand & RA & $\begin{array}{c}\text { conv. } \\
(\%)\end{array}$ & $\begin{array}{c}\text { ee of } 9 \\
(\%)^{\mathrm{b}}\end{array}$ \\
\hline $\mathbf{1}$ & & - & $\mathbf{2 8}$ & $6(+)$ \\
$\mathbf{2}$ & $(S)-\mathbf{L 1}$ & $\mathrm{NaBArF}$ & $>99$ & $85(+)$ \\
3 & & $\mathrm{NaBArF}^{\mathrm{c}}$ & 95 & $92(+)$ \\
\hline 4 & & - & 23 & $10(-)$ \\
5 & $(R, S)-\mathbf{L} 2$ & $\mathrm{KBArF}^{2}$ & $>99$ & $83(+)$ \\
6 & & $\mathrm{KBArF}^{\mathrm{c}}$ & $>99$ & $93(+)$ \\
\hline 7 & & - & 17 & $\mathrm{rac}$ \\
8 & $(S, S)-\mathbf{L} 3$ & $\mathrm{RbBArF}^{2}$ & $>99$ & $74(+)$ \\
9 & & $\mathrm{RbBArF}^{\mathrm{c}}$ & 93 & $89(+)$ \\
\hline
\end{tabular}

${ }^{\mathrm{a}}$ See footnote a in Table 1 for details, with the following remarks: Reaction conditions are shown in Scheme $4 .{ }^{\mathrm{b}}$ Absolute configuration is unknown, and the sign of the optical rotation is provided. ${ }^{c}$ Reaction performed at $25^{\circ} \mathrm{C}$.

To elucidate the structure of the catalytic species, complexation experiments between $\left[\mathrm{Rh}\left(\kappa^{2} \mathrm{O}, \mathrm{O}^{\prime}\right.\right.$-acac $\left.)\left(\mathrm{CO}_{2}\right)\right]$, ligand $(R, S)$-L2, and one representative RA (KBArF) were performed. These compounds were reacted at $40{ }^{\circ} \mathrm{C}$ under 10 bar of 1:1 $\mathrm{H}_{2} / \mathrm{CO}$. Interestingly, the expected hydridodicarbonyl chelate $\left[\mathrm{Rh}(\mathrm{H})(\mathrm{CO})_{2}\left(\kappa^{2} \mathrm{P}, \mathrm{P}^{\prime}-\operatorname{KBArF}^{*}(R, S)-\mathbf{L} \mathbf{2}\right)\right]$ was efficiently formed. ${ }^{13}$ NMR analysis showed the hydrido signal as a broad and partially resolved multiplet centered at $-10.38 \mathrm{ppm}\left({ }^{2} J_{\mathrm{PH}}=22 \mathrm{~Hz}\right)$. The value of this coupling constant indicates that the system undergoes an equilibrium between two hydrido-dicarbonyl rhodium complexes with the two P-ligating groups coordinated in an equatorial-equatorial or apical-equatorial fashion to a trigonal-bipyramidal rhodium center. ${ }^{14}$ The complexation behavior of ligand $(R, S)$-L2 is different from that of ligand $(S)$-L1, which lacks the biaryl core in the regulation site. NMR analysis on the hydrido-dicarbonyl chelate derived from $(S)$-Li indicated that the two P-ligating groups coordinated in an equatorial-equatorial fashion ${ }^{14}$ (see Experimental Section and Supporting Information). This difference in coordination behavior between ligands with or without the $\left[1,1^{\prime}-\right.$ binaphthalene]-2,2'-diol motif in the regulation site could account for the higher activity of ligand $(R, S)$ - $\mathbf{L} 2$ in the AHF of heterocyclic alkenes.

In summary, challenging heterocyclic olefins were efficiently hydroformylated in terms of high regio- and enantioselectivities with supramolecularly regulated rhodium complexes derived from bisphosphite ligands L1-3. Small amounts of polyether-binder RAs were shown to regulate the activity of the AHF catalysts. The distribution of the enantiomers was biased in some examples (rhodium complexes of a ligand and an RA enabled up to $86 \%$ higher enantioselectivities compared with those obtained in the reactions of the corresponding complexes without an RA). In the AHF of 2,5dihydrofuran, we have demonstrated the potential of our supramolecularly regulated catalysts, as the use of an alkali metal BArF salt as RA increased enantioselectivity (up to $33 \%$ ee), reversed the regioselectivity of the reaction, or completely suppressed the formation of the side-product.

\section{EXPERIMENTAL SECTION}

General information: All syntheses were carried out using chemicals as purchased from commercial sources unless otherwise cited. All manipulations and reactions were performed under an inert atmosphere. Glassware was dried in vacuo before use with a hot air gun. All solvents were dried and deoxygenated by using a solvent purification system (SPS). Silica gel 6o (230-400 mesh) or Silica-C18 (200-400 mesh) were used for column chromatography. NMR spectra were recorded in $\mathrm{CDCl}_{3}$ unless otherwise cited. ${ }^{1} \mathrm{H}$ and ${ }^{13} \mathrm{C}$ NMR chemical shifts are quoted in ppm relative to residual solvent peaks, whereas ${ }^{31} \mathrm{P}$ NMR chemical shifts are quoted in ppm relative to $85 \%$ phosphoric acid in water. IR spectra were recorded using attenuated total reflection (ATR) unless otherwise cited. High-resolution mass spectra (HRMS) were recorded using an electrospray ionization (ESI) method in positive mode for the ligands $(\mathbf{L 1}-\mathbf{3})$ and diols $((R)-\mathbf{D 2}$ and $(S)$-D2) and matrix-assited laser desorption ionization (MALDI) in positive mode for $\left[\mathrm{Rh}(\mathrm{H})(\mathrm{CO})_{2}\left(\kappa^{2} \mathrm{P}, \mathrm{P}^{\prime}-\mathrm{KBArF}^{*}(S)-\mathbf{L 1}\right)\right] \quad$ and $\left[\mathrm{Rh}(\mathrm{H})(\mathrm{CO})_{2}\left(\kappa^{2} \mathrm{P}, \mathrm{P}^{\prime}-\mathrm{KBArF}^{\circ}(R, S)-\mathbf{L 2}\right)\right]$, using, in all cases, a time-of-flight (TOF) detector. Melting points were determined in open capillaries and are uncorrected. Enantiomeric excesses were determined by GC equipped with a FID detector using chiral stationary phases.

Synthesis of ligand (S)-L1: $(S)-5,5$ '-6,6'-Tetramethyl-3,3'di-tert-butyl-1,1'-biphenyl-2,2'-diol (265 mg, $0.75 \mathrm{mmol}$ ) was azeotropically dried with toluene $(3 \times 2 \mathrm{~mL})$, dissolved in anhydrous toluene (ca. $10 \mathrm{~mL}$ ), and slowly added to a stirred solution of $\mathrm{PCl}_{3}(82.4 \mu \mathrm{L}, 0.94 \mathrm{mmol})$ and $\mathrm{NEt}_{3}(297 \mu \mathrm{L}, 2.14$ mmol) in dry toluene ( $\mathrm{ca} .10 \mathrm{~mL}$ ) at $\mathrm{o}{ }^{\circ} \mathrm{C}$. The solution was allowed to reach room temperature and was stirred overnight. The turbid reaction mixture was filtered, and the solvent evaporated under reduced pressure. The resulting residue was dissolved in ca. $10 \mathrm{~mL}$ of dry toluene and $\mathrm{NEt}_{3}(297$ $\mu \mathrm{L}, 2.14 \mathrm{mmol})$. A solution of the tetraethylenglycol $(66.8 \mathrm{mg}$, $0.34 \mathrm{mmol}$ in ca. $10 \mathrm{~mL}$ of toluene) was slowly added to the previous solution, and the mixture was allowed to react overnight at room temperature. The reaction mixture was filtered, and the solvent was evaporated under reduced pressure. The resulting crude mixture was purified by column chromatography on silica gel $\mathrm{C}_{1} 8$ using acetonitrile/EtOAc 1:1 as the elution solvent to obtain the expected bisphosphite 
ligand $(S)$-L1 as a white solid. Isolated $312 \mathrm{mg}, 83 \%$ yield. ${ }^{1} \mathrm{H}$ NMR $\left(\mathrm{CDCl}_{3}, 500 \mathrm{MHz}\right): \delta 7.15(\mathrm{~s}, 2 \mathrm{H}), 7.11(\mathrm{~s}, 2 \mathrm{H}), 3.96-3.91$ $(\mathrm{m}, 2 \mathrm{H}), 3.6 \mathrm{o}-3.55(\mathrm{~m}, 8 \mathrm{H}), 3.54-3.48(\mathrm{~m}, 6 \mathrm{H}), 2.25(\mathrm{~s}, 6 \mathrm{H})$, $2.24(\mathrm{~s}, 6 \mathrm{H}), 1.85(\mathrm{~s}, 6 \mathrm{H}), 1.78(\mathrm{~s}, 6 \mathrm{H}), 1.45(\mathrm{~s}, 18 \mathrm{H}), 1.42(\mathrm{~s}$, $\left.{ }_{18 H}\right) .{ }^{13} \mathrm{C}\left\{{ }^{1} \mathrm{H}\right\}$ NMR $\left(\mathrm{CDCl}_{3}, 125 \mathrm{MHz}\right): \delta 145.5,145.5,138.2$, 138.2, 137.0, 135.1, 134.5, 132.5, 131.9, 131.8, 131.7, 130.8, 130.8, 128.2, 127.9, 71.0, 70.9, 70.7, 63.6, 63.6, 34.8, 34.8, 31.5, 31.5, 31.3, 20.6, 16.9, 16.7. ${ }^{31} \mathrm{P}\left\{{ }^{1} \mathrm{H}\right\}$ NMR $\left(\mathrm{CDCl}_{3}, 202 \mathrm{MHz}\right): \delta 132.6$ (s). HRMS-ESI-TOF $(\mathrm{m} / \mathrm{z})$ : $[\mathrm{M}+\mathrm{Na}]^{+}$calcd for $\mathrm{C}_{56} \mathrm{H}_{80} \mathrm{O}_{9} \mathrm{P}_{2} \mathrm{Na}$, 981.5170; found, 981.5191. $[\alpha]_{\mathrm{D}}^{25}=+371.8$ (c o.1, DCM). IR (neat, $\left.\mathrm{cm}^{-1}\right) \bar{v} 2963,2867,1254,1027,870 . \mathrm{mp} 71.2-72.6^{\circ} \mathrm{C}$.

Synthesis of ligand $(\boldsymbol{R}, \boldsymbol{S})-\mathbf{L 2}$ : A mixture of $(R)-\left[1,1^{\prime}-\right.$ binaphthalene]-2,2'-diol $\quad(1.75 \mathrm{~g}, \quad 6.13 \mathrm{mmol}), \quad 2-(2-$ hydroxyethoxy)ethyl-4-methylbenzenesulfonate ${ }^{15}$ (3.19 g, 12.3 $\mathrm{mmol})$, and $\mathrm{K}_{2} \mathrm{CO}_{3}(3.64 \mathrm{~g}, 26.3 \mathrm{mmol})$ in dry acetonitrile $(53$ $\mathrm{mL}$ ) was refluxed for $72 \mathrm{~h}$. The reaction mixture was filtered and then concentrated under reduced pressure. The crude product was purified by column chromatography over silica gel (EtOAc/MeOH 95:5 as eluent) to afford the desired product, $(R)-2,2$ '- $\left(\left(\left(\left[1,1^{\prime}\right.\right.\right.\right.$-binaphthalene $]-2,2 '-$ diylbis(oxy))bis(ethane-2,1-diyl))bis(oxy))diethanol ((R)-D2; see the Supporting Information for the spectra) as a clear brown oil. Isolated $1.33 \mathrm{~g}, 46 \%$ yield. ${ }^{1} \mathrm{H} \mathrm{NMR}\left(\mathrm{CDCl}_{3}, 500\right.$ MHz,): $\delta 7.95(\mathrm{~d}, J=9.1 \mathrm{~Hz}, 2 \mathrm{H}), 7.87(\mathrm{~d}, J=8.1 \mathrm{~Hz}, 2 \mathrm{H}), 7.43$ $(\mathrm{d}, J=9.1 \mathrm{~Hz}, 2 \mathrm{H}), 7.35-7.32(\mathrm{~m}, 2 \mathrm{H}), 7.24-7.21(\mathrm{~m}, 2 \mathrm{H}), 7.16$ $(\mathrm{s}, 1 \mathrm{H}), 7.14(\mathrm{~s}, 1 \mathrm{H}), 4.17-4.13(\mathrm{~m}, 2 \mathrm{H}), 4.03-3.99(\mathrm{~m}, 2 \mathrm{H})$, 3.53-3.49 (m, 2H), 3.45-3.38 (m, 6H), 3.22-3.15 (m, $4 \mathrm{H}), 2.56$ $(\mathrm{t}, J=6.6 \mathrm{~Hz}, 2 \mathrm{H}) \cdot{ }^{13} \mathrm{C}\left\{{ }^{1} \mathrm{H}\right\} \mathrm{NMR}\left(\mathrm{CDCl}_{3}, 125 \mathrm{MHz}\right): \delta$ 154.4, 134.2, 129.6, 129.5, 128.0, 126.5, 125.6, 123.9, 120.8, 116.1, 72.5, 70.0, 69.7, 61.7. HRMS-ESI-TOF $(\mathrm{m} / \mathrm{z}):[\mathrm{M}+\mathrm{Na}]^{+}$calcd for $\mathrm{C}_{28} \mathrm{H}_{30} \mathrm{NaO}_{6}$, 485.1935; found, 485.1923. $[\alpha]_{\mathrm{D}}^{25}=+43.1$ (c o.1, DCM). IR (neat, $\mathrm{cm}^{-1}$ ) $\bar{v}$ 3414, 2927, 2869, 1240, 1054. Ligand $(R, S)$-L2 was synthesized from $(S)$-5,5'-6,6' -tetramethyl-3,3' di-tert-butyl-1,1'-biphenyl-2,2'-diol (424 mg, $1.2 \mathrm{mmol})$, which was azeotropically dried with toluene $(3 \times 2 \mathrm{~mL})$ under argon atmosphere. The remaining solid was dissolved in anhydrous toluene (ca. $20 \mathrm{~mL}$ ) and slowly added to a stirred solution of $\mathrm{PCl}_{3}(132 \mu \mathrm{L}, 1.51 \mathrm{mmol})$ and $\mathrm{NEt}_{3}(476 \mu \mathrm{L}, 3.42 \mathrm{mmol})$ in dry toluene (ca. $20 \mathrm{~mL}$ ) at $\mathrm{o}{ }^{\circ} \mathrm{C}$. The solution was allowed to reach room temperature and was stirred overnight. The turbid reaction mixture was filtered, and the solvent evaporated under reduced pressure. The resulting residue was dissolved in ca. $20 \mathrm{~mL}$ of dry toluene and $\mathrm{NEt}_{3}(476 \mu \mathrm{L}, 3.42$ mmol). A solution of the diol (R)-D2 $(255 \mathrm{mg}, 0.55 \mathrm{mmol}$ in ca. $20 \mathrm{~mL}$ of toluene) was slowly added to the previous solution, and the mixture was allowed to react overnight at room temperature. The reaction mixture was filtered, and the solvent evaporated under reduced pressure. The resulting crude mixture was purified by column chromatography on silica gel $\mathrm{C}_{1} 8$ using acetonitrile/EtOAc 1:1 as the elution solvent to obtain the expected bisphosphite ligand $(R, S)$-L2 as a white solid. Isolated $554 \mathrm{mg}, 82 \%$ yield, quantitatively pure by ${ }^{31} \mathrm{P}$ NMR. ${ }^{1} \mathrm{H}$ NMR $\left(\mathrm{CDCl}_{3}, 400 \mathrm{MHz}\right): \delta_{7.82}\left(\mathrm{~s},{ }_{1} \mathrm{H}\right), 7.8 \mathrm{o}(\mathrm{s}$, $1 \mathrm{H}), 7.76(\mathrm{~s}, 1 \mathrm{H}), 7.74(\mathrm{~s}, 1 \mathrm{H}), 7.32(\mathrm{~s}, 1 \mathrm{H}), 7.29(\mathrm{~s}, 1 \mathrm{H})$, 7.25-7.24 (m, $1 \mathrm{H}), 7.23-7.22(\mathrm{~m}, 1 \mathrm{H}), 7.18-7.09(\mathrm{~m}, 8 \mathrm{H})$, 4.01-3.99 (m, $4 \mathrm{H}), 3.56-3.52(\mathrm{~m}, 2 \mathrm{H}), 3.39-3.36\left(\mathrm{~m},{ }_{4} \mathrm{H}\right)$, 3.20-3.14 (m, $2 \mathrm{H}), 2.94-2.91(\mathrm{~m}, 4 \mathrm{H}), 2.26(\mathrm{~s}, 6 \mathrm{H}), 2.26(\mathrm{~s}$, $6 \mathrm{H}), 1.87(\mathrm{~s}, 6 \mathrm{H}), 1.79(\mathrm{~s}, 6 \mathrm{H}), 1.43(\mathrm{~s}, 18 \mathrm{H}), 1.40(\mathrm{~s}, 18 \mathrm{H})$. ${ }^{13} \mathrm{C}\left\{{ }^{1} \mathrm{H}\right\} \mathrm{NMR}\left(\mathrm{CDCl}_{3}, 125 \mathrm{MHz}\right): \delta 154.3,145.6,138.2,137.1,135.1$, 134.4, 134.2, 132.5, 131.9, 131.6, 130.9, 129.5, 129.4, 128.1, 127.9, $127.9,126.4,125.6,123.8,120.7,115.8,70.9,70.1,69.5,63.6,34.8$, 34.8, 31.4, 31.3, 20.6, 20.6, 16.9, 16.7. ${ }^{31} \mathrm{P}\left\{{ }^{1} \mathrm{H}\right\}$ NMR: $\left(\mathrm{CDCl}_{3}, 2 \mathrm{O} 2\right.$
$\mathrm{MHz}) \delta 133.8(\mathrm{~s})$. HRMS-ESI-TOF $(\mathrm{m} / \mathrm{z}):[\mathrm{M}+\mathrm{Na}]^{+}$calcd for $\mathrm{C}_{76} \mathrm{H}_{92} \mathrm{NaO}_{10} \mathrm{P}_{2}$, 1249.6058; found, 1249.6037. $[\alpha]_{\mathrm{D}}^{25}=+331.2(c$ o.1, DCM). IR (neat, $\mathrm{cm}^{-1}$ ) $\bar{v} 2953,2868,1227,1023 . \mathrm{mp}$ $89.3^{-} 90.7^{\circ} \mathrm{C}$.

Synthesis of ligand $(S, S)-L_{3}$ : A mixture of $(S)-\left[1,1^{\prime}-\right.$ binaphthalene]-2,2'-diol (2 g, $6.93 \mathrm{mmol})$, 2-(2hydroxyethoxy)ethyl-4-methylbenzenesulfonate ${ }^{15} \quad(3.68 \mathrm{~g}$, $13.9 \mathrm{mmol})$ and $\mathrm{K}_{2} \mathrm{CO}_{3}(4.12 \mathrm{~g}, 29.8 \mathrm{mmol})$ in dry acetonitrile (6o $\mathrm{mL}$ ) was refluxed for $72 \mathrm{~h}$. The reaction mixture was filtered and then concentrated under reduced pressure. The crude product was purified by column chromatography over silica gel (EtOAc/MeOH 95:5 as eluent) to afford $(S)-\mathbf{2 , 2}$ ((([1,1'-binaphthalene]-2,2'-diylbis(oxy))bis(ethane-2,1-

diyl))bis(oxy))diethanol $((S)$-D2, see the Supporting Information for the spectra) as a clear brown oil. Isolated $1.5 \mathrm{~g}$, $47 \%$ yield. ${ }^{1} \mathrm{H}$ NMR $\left(\mathrm{CDCl}_{3}, 500 \mathrm{MHz}\right): \delta 7.95(\mathrm{~d}, J=9.1 \mathrm{~Hz}$, $2 \mathrm{H}), 7.87(\mathrm{~d}, J=8.1 \mathrm{~Hz}, 2 \mathrm{H}), 7.43(\mathrm{~d}, J=9.1 \mathrm{~Hz}, 2 \mathrm{H}), 7.35-7.32$ (m, 2H), 7.24-7.21 (m, 2H), 7.15 (s, $1 \mathrm{H}), 7.14(\mathrm{~s}, 1 \mathrm{H}), 4.17-4.13$ $(\mathrm{m}, 2 \mathrm{H}), 4.03-3.99(\mathrm{~m}, 2 \mathrm{H}), 3.53-3.49(\mathrm{~m}, 2 \mathrm{H}), 3.45-3.40(\mathrm{~m}$, $6 \mathrm{H})$, 3.22-3.15 (m, $4 \mathrm{H}), 2.53($ br s, $2 \mathrm{H}) .{ }^{13} \mathrm{C}\left\{{ }^{1} \mathrm{H}\right\}$ NMR $\left(\mathrm{CDCl}_{3}\right.$, $125 \mathrm{MHz}): \delta 154.4,134.2,129.6$, 129.5, 128.0, 126.5, 125.6, 124.0, 120.8, 116.1, 72.5, 70.0, 69.7, 61.7. HRMS-ESI-TOF $(\mathrm{m} / \mathrm{z})$ : $[\mathrm{M}+\mathrm{Na}]^{+}$calcd for $\mathrm{C}_{28} \mathrm{H}_{30} \mathrm{NaO}_{6}, 485.1935$; found, 485.1927 . $[\alpha]_{\mathrm{D}}^{25}=-25.5$ (c o.1, DCM). IR (neat, $\mathrm{cm}^{-1}$ ) v 3419, 2927, 2869, 1240, 1055. Ligand $(S, S)-\mathbf{L}_{3}$ was synthesized following the general strategy. (S)-5,5'-6,6'-tetramethyl-3,3' -di-tert-butyl1,1'-biphenyl-2,2'-diol (6oo mg, $1.7 \mathrm{mmol}$ ) was azeotropically dried with toluene $(3 \times 2 \mathrm{~mL})$ under an argon atmosphere, dissolved in anhydrous toluene (ca. $23 \mathrm{~mL}$ ), and slowly added to a stirred solution of $\mathrm{PCl}_{3}(186 \mu \mathrm{L}, 2.13 \mathrm{mmol})$ and $\mathrm{NEt}_{3}(673$ $\mu \mathrm{L}, 4.84 \mathrm{mmol}$ ) in dry toluene (ca. $23 \mathrm{~mL}$ ) at o ${ }^{\circ} \mathrm{C}$. The solution was allowed to reach room temperature and was stirred overnight. The turbid reaction mixture was filtered, and the solvent evaporated under reduced pressure. The resulting residue was dissolved in ca. $23 \mathrm{~mL}$ of dry toluene and $\mathrm{NEt}_{3}$ (673 $\mu \mathrm{L}, 4.84 \mathrm{mmol})$. A solution of the diol $(S)-\mathbf{D}_{2}$ (360 $\mathrm{mg}$, $0.78 \mathrm{mmol}$ in ca. $23 \mathrm{~mL}$ of toluene) was slowly added to the previous solution and allowed to react overnight at room temperature. The reaction mixture was filtered, and the solvent was evaporated under reduced pressure. The resulting crude mixture was purified by column chromatography on silica gel $\mathrm{C}_{1} 8$ using acetonitrile/EtOAc 1:1 as the elution solvent to provide the expected bisphosphite ligand $(S, S)-\mathbf{L}_{3}$ as a white solid. Isolated $589 \mathrm{mg}, 62 \%$ yield, quantitatively pure by ${ }^{31} \mathrm{P}$ NMR. ${ }^{1} \mathrm{H}$ NMR $\left(\mathrm{CDCl}_{3}, 500 \mathrm{MHz},\right): \delta_{7.83}\left(\mathrm{~s},{ }_{1} \mathrm{H}\right)$, $7.81(\mathrm{~s}, 1 \mathrm{H}), 7.77(\mathrm{~s}, 1 \mathrm{H}), 7.75(\mathrm{~s}, 1 \mathrm{H}), 7.30(\mathrm{~s}, 1 \mathrm{H}), 7.28(\mathrm{~s}, 1 \mathrm{H})$, 7.27-7.24 (m, 2H), 7.17-7.14 (m, 6H), 7.11 (s, $1 \mathrm{H}), 7.10(\mathrm{~m}, 1 \mathrm{H})$, 4.02-3.97 (m, $4 \mathrm{H}), 3.52-3.46(\mathrm{~m}, 2 \mathrm{H}), 3.43-3.39(\mathrm{~m}, 2 \mathrm{H})$, $3.36-3.31(\mathrm{~m}, 2 \mathrm{H}), 3.20-3.14(\mathrm{~m}, 2 \mathrm{H}), 2.94-2.90(\mathrm{~m}, 2 \mathrm{H})$, 2.84- $2.81(\mathrm{~m}, 2 \mathrm{H}), 2.26(\mathrm{~s}, 12 \mathrm{H}), 1.86(\mathrm{~s}, 6 \mathrm{H}), 1.79(\mathrm{~s}, 6 \mathrm{H}), 1.42$ $(\mathrm{s}, 18 \mathrm{H}), 1.39(\mathrm{~s}, 18 \mathrm{H}) \cdot{ }^{13} \mathrm{C}\left\{{ }^{1} \mathrm{H},{ }^{3} \mathrm{P}\right\}$ NMR $\left(\mathrm{CDCl}_{3}, 125 \mathrm{MHz}\right)$ : $\delta 154.3,145.5,138.2,137.1,135.1,134.4,134.2,132.5,131.9,131.6$, $130.9,129.5,129.4,128.1,127.9,127.9,126.4,125.6,123.8,120.6$, $115.7,70.9,70.1,69.5,63.8,34.8,34.8,31.4,31.3,20.6,17.0,16.7$. ${ }^{31} \mathrm{P}\left\{{ }^{1} \mathrm{H}\right\}$ NMR $\left(\mathrm{CDCl}_{3}, 202 \mathrm{MHz}\right): \delta 134.7(\mathrm{~s})$. HRMS-ESI-TOF $(\mathrm{m} / \mathrm{z})$ : $[\mathrm{M}+\mathrm{Na}]^{+}$calcd for $\mathrm{C}_{76} \mathrm{H}_{92} \mathrm{NaO}_{10} \mathrm{P}_{2}, 1249.6058$; found, 1249.6032. $[\alpha]_{\mathrm{D}}^{25}=+279.5$ (c o.1, DCM). IR (neat, $\mathrm{cm}^{-1}$ ) $\bar{v} 2954,2867,1227,1022 . \mathrm{mp} \mathrm{107.9-109.3}{ }^{\circ} \mathrm{C}$.

General procedure for Rh-mediated asymmetric hydroformylations 
To a $2 \mathrm{~mL}$ vial equipped with a magnetic bar in a glovebox filled with nitrogen were added ligand $\mathbf{L 1}-3$ (ca. $2.7 \mu \mathrm{mol}$ in 36o $\mu \mathrm{L}$ of toluene), alkali BArF salt (ca. $3.6 \mu \mathrm{mol}$ in $27 \mu \mathrm{L}$ of THF), and $\left[\mathrm{Rh}\left(\kappa^{2} \mathrm{O}, \mathrm{O}^{\prime}\right.\right.$-acac) $\left.(\mathrm{CO})_{2}\right]$ (ca. $2.3 \mu \mathrm{mol}$ in $65 \mu \mathrm{L}$ of toluene). Substrate (ca. $230 \mu \mathrm{mol}$ ) and additional toluene were charged, obtaining the mixture toluene/THF $(97: 3 \mathrm{v} / \mathrm{v})$ and providing the desired final concentration of substrate, $0.26 \mathrm{M}$. In the cases of vinyl derivatives $(\mathbf{1 a}-\mathbf{c})$ and styrene (1d), $n$-dodecane (ca. $69 \mu \mathrm{mol}$ ) was added as an internal standard. The vial was transferred into an autoclave and taken out of the glovebox. The autoclave was purged three times with syngas (at a pressure not higher than that required for the reaction) and, finally, the autoclave was pressurized with the corresponding pressure of syngas. The reaction mixture was stirred at $40{ }^{\circ} \mathrm{C}$ (water bath) for $18 \mathrm{~h}$. The reaction was cooled, and the pressure was carefully released in a well-ventilated hood.

\section{Determination of enantiomeric excesses and configura- tion of hydroformylated products}

Characterization of hydroformylation products of 1a-e, 4, 7 and $\mathbf{8}$ have been described previously in the literature, and spectroscopic data were in agreement with those reported. ${ }^{16}$ Conversion, regioselectivity and enantiomeric excesses of hydroformylated products of vinyl derivatives (1a-c) and styrene (1d) were determined by GC from the crude mixtures, using $n$-dodecane as an internal standard, with a $\beta$-Dex 225 column $(30 \mathrm{~m} \times 0.25 \mathrm{~mm} \times 0.25 \mu \mathrm{m})$. Conversion and regioselectivity for (allyloxy)trimethylsilane (1e) were determined by ${ }^{1} \mathrm{H}$ NMR, and the enantiomeric excesses, by GC analysis with $\beta$-Dex 225 column $(30 \mathrm{~m} \times 0.25 \mathrm{~mm} \times 0.25 \mu \mathrm{m}$ ) from the crude reaction mixture. Conversion and isomerization of 2,5-dihydrofuran (4) and 2,3-dihydrofuran (7) were determined by ${ }^{1} \mathrm{H}$ NMR, and the enantiomeric excesses, by GC analysis with $\beta$-Dex 225 column $(30 \mathrm{~m} \times 0.25 \mathrm{~mm} \times 0.25$ $\mu \mathrm{m})$ from the crude reaction mixture. Conversion and regioselectivity of cis-4,7-dihydro-1,3-dioxepin (8) were determined by ${ }^{1} \mathrm{H}$ NMR, and enantiomeric excesses, by GC from the crude mixture with a $\beta$-Dex 225 column $(30 \mathrm{~m} \times 0.25 \mathrm{~mm}$ $\times 0.25 \mu \mathrm{m})$. Optical rotation of aldehyde $9\left([\alpha]_{\mathrm{D}}^{25}=+70.2(c\right.$ o.1, THF)) was determined from the reaction mixture with a 93\% ee (entry 6 in Table 4 ) distilling in a Kugelrohr apparatus $\left(40^{\circ} \mathrm{C}, 5 \times 10^{-2}\right.$ mbar $)$, obtaining aldehyde 9 with a final enantiomeric excess of $91 \%$ ee $\left({ }^{1} \mathrm{H}\right.$ NMR spectrum and GC chromatogram are available in the Supporting Information).

Vinyl acetate (1a): ${ }^{17}$ Temperature program: $100{ }^{\circ} \mathrm{C}$ for $5 \mathrm{~min}$ then $4{ }^{\circ} \mathrm{C} / \mathrm{min}$ to $160{ }^{\circ} \mathrm{C}$. Retention times: $2.5 \mathrm{~min}$ for $\mathbf{1 a}, 7.2$ $\min$ for $(R)$-2a, $9.1 \mathrm{~min}$ for $(S)$-2a, and $12.2 \mathrm{~min}$ for $3 \mathbf{a}$.

Vinyl propionate (1b): ${ }^{16 a}$ Temperature program: Isothermal $100{ }^{\circ} \mathrm{C}$. Retention times: $2.8 \mathrm{~min}$ for $\mathbf{1 b}, 9.1 \mathrm{~min}$ for $(R)-\mathbf{2} \mathbf{b}$, $10.5 \mathrm{~min}$ for $(S)-\mathbf{2 b}$, and $21.1 \mathrm{~min}$ for $\mathbf{3} \mathbf{b}$.

Vinyl benzoate (1c): ${ }^{16 a}$ Temperature program: Isothermal 135 ${ }^{\circ} \mathrm{C}$. Retention times: $6.6 \mathrm{~min}$ for $\mathbf{1 c}, \mathbf{2 5} \cdot 3 \mathrm{~min}$ for $(R)-\mathbf{2 c}, \mathbf{2 7 . 6}$ $\min$ for $(S)$-2c, and 57.3 min for $3 \mathbf{c}$.

Styrene (1d): ${ }^{17}$ Temperature program: $100{ }^{\circ} \mathrm{C}$ for 5 min then 4 ${ }^{\circ} \mathrm{C} / \mathrm{min}$ to $160{ }^{\circ} \mathrm{C}$. Retention times: $4.6 \mathrm{~min}$ for $\mathbf{1 d}, 12.5 \mathrm{~min}$ for $(R)-2 d, 12.8 \mathrm{~min}$ for $(S)$-2d, and $16.3 \mathrm{~min}$ for $3 \mathbf{d}$.

(Allyloxy)trimethylsilane (1e): ${ }^{16 \mathrm{~d}}$ Temperature program: Isothermal $70{ }^{\circ} \mathrm{C}$. Retention times: $24.5 \mathrm{~min}$ for $(R)$-2e, and 25.6 $\min$ for $(S)$-2e. 2,5-dihydrofuran (4) and 2,3-dihydrofuran (7):9 Temperature program: $40{ }^{\circ} \mathrm{C}$ for $5 \mathrm{~min}, 5{ }^{\circ} \mathrm{C} / \mathrm{min}$ to $150{ }^{\circ} \mathrm{C}$, hold for $1 \mathrm{~min}$, and then $10{ }^{\circ} \mathrm{C} / \mathrm{min}$ to $210{ }^{\circ} \mathrm{C}$. Retention times: $22.7 \mathrm{~min}$ for $(R)-5$, and $23.3 \mathrm{~min}$ for $(S)-5,24.7 \mathrm{~min}$ for $(S)-6$, and $25.6 \mathrm{~min}$ for $(R)-6$.

cis-4,7-dihydro-1,3-dioxepin (8): Temperature program: 40 ${ }^{\circ} \mathrm{C}$, hold for $5 \mathrm{~min}, 2{ }^{\circ} \mathrm{C} / \mathrm{min}$ to $150{ }^{\circ} \mathrm{C}$, hold for $1 \mathrm{~min}$, and then $10{ }^{\circ} \mathrm{C} / \mathrm{min}$ to $210^{\circ} \mathrm{C}$. Retention times: $48.1 \mathrm{~min}$ for $(+)-9$ and $49.1 \mathrm{~min}$ for $(-)-9 .{ }^{18}$

\section{Direct formation of $\left[\mathrm{Rh}(\mathrm{H})(\mathrm{CO})_{2}\left(\kappa^{2} \mathrm{P}, \mathrm{P}^{\prime}-(\mathrm{KBArF} \cdot(S)-\mathrm{L1})\right]\right.$}

A $0.03 \mathrm{M}$ solution of $(S)-\mathbf{L 1}(12.2 \mathrm{mg}, 12.7 \mu \mathrm{mol})$, [Rh( $\kappa^{2} \mathrm{O}, \mathrm{O}^{\prime}-$ acac) $\left.(\mathrm{CO})_{2}\right](3.31 \mathrm{mg}, 12.7 \mu \mathrm{mol})$ and $\operatorname{KBArF}(14.2 \mathrm{mg}, 16.5$ $\mu \mathrm{mol})$ in $\mathrm{C}_{7} \mathrm{D}_{8} / \mathrm{C}_{4} \mathrm{D}_{8} \mathrm{O}(97: 3 \mathrm{v} / \mathrm{v})$ were transferred to a $25 \mathrm{ml}$ autoclave reactor, which was pressurized to 10 bar of syngas (1:1 $\left.\mathrm{H}_{2} / \mathrm{CO}\right)$ and warmed to $40{ }^{\circ} \mathrm{C}$. The mixture was allowed to stir for $2 \mathrm{~h}$. The reactor was cooled to room temperature and depressurized in a well-ventilated fume hood, and the reaction mixture was transferred to $5 \mathrm{~mm}$ HP-NMR sapphire tube. The tube was pressurized with syngas $\left(1: 1 \mathrm{H}_{2} / \mathrm{CO}, 10\right.$ bar) and the HP-NMR spectra were collected at $25{ }^{\circ} \mathrm{C}$ (see Supporting Information). MS samples were immediately recorded under $\mathrm{N}_{2}$ after depressurizing the autoclave. Spectroscopic data obtained from this solution was in agreement with the quantitative formation of the $\left[\mathrm{Rh}(\mathrm{H})(\mathrm{CO})_{2}\left(\kappa^{2} \mathrm{P}, \mathrm{P}^{\prime}-\mathrm{KBArF} \cdot(S)-\mathbf{L 1}\right)\right] \quad$ complex: ${ }^{1} \mathrm{H} \quad \mathrm{NMR}$ $\left(\mathrm{C}_{7} \mathrm{D}_{8} / \mathrm{C}_{4} \mathrm{D}_{8} \mathrm{O}(97: 3 \mathrm{v} / \mathrm{v}), 500 \mathrm{MHz}\right): \delta_{7.23}(\mathrm{~s}, 2 \mathrm{H}), 7.16(\mathrm{~s}, 2 \mathrm{H})$, $3.90-3.88(\mathrm{~m}, 2 \mathrm{H}), 3.37-3.34(\mathrm{~m}, 2 \mathrm{H}), 2.95-2.85(\mathrm{~m}, 1 \mathrm{OH})$, $2.67-2.64(\mathrm{~m}, 2 \mathrm{H}), 2.11(\mathrm{~s}, 6 \mathrm{H}), 1.98(\mathrm{~s}, 6 \mathrm{H}), 1.65(\mathrm{~s}, 6 \mathrm{H}), 1.58$ $(\mathrm{s}, 6 \mathrm{H}), 1.52(\mathrm{~s}, 18 \mathrm{H}), 1.48(\mathrm{~s}, 18 \mathrm{H}),-10.83\left(\mathrm{~d}, J_{\mathrm{PH}}=4.8 \mathrm{~Hz}\right.$, $\left.{ }_{1 H} \mathrm{H}\right) .{ }^{13} \mathrm{C}\left\{{ }^{1} \mathrm{H}\right\} \operatorname{NMR}\left(\mathrm{C}_{7} \mathrm{D}_{8} / \mathrm{C}_{4} \mathrm{D}_{8} \mathrm{O}(97: 3 \mathrm{v} / \mathrm{v}), 125 \mathrm{MHz}\right): \delta 191.2$, 147.6, 144.5, 136.1, 136.0, 135.7, 134.9, 133.7, 133.5, 130.6, 130.3, 130.0, 129.8, 129.6, 129.1, 126.4, 118.7, 69.6, 69.5, 69.4, 67.0, 35.6, 34.9, 33.0, 31.2, 20.2, 20.0, 16.3, 16.3. ${ }^{31} \mathrm{P} \quad \mathrm{NMR}$ $\left(\mathrm{C}_{7} \mathrm{D}_{8} / \mathrm{C}_{4} \mathrm{D}_{8} \mathrm{O}(97: 3 \mathrm{v} / \mathrm{v}), 202 \mathrm{MHz}\right): \delta 142.6\left(\mathrm{~d}, J_{\mathrm{RhP}}=242.9\right.$ $\mathrm{Hz})$. HMRS-MALDI-TOF $(\mathrm{m} / \mathrm{z})$ : $[\mathrm{M}-\mathrm{H}-\mathrm{CO}-\mathrm{K}]^{+}$calcd for $\mathrm{C}_{57} \mathrm{H}_{80} \mathrm{O}_{10} \mathrm{P}_{2} \mathrm{Rh}, 1089.4276$, found, 1089.4264. Attempts to isolate this complex in analytically pure form failed.

\section{Direct formation of $\left[\mathrm{Rh}(\mathrm{H})(\mathrm{CO})_{2}\left(\kappa^{2} \mathrm{P}, \mathrm{P}^{\prime}-(\operatorname{KBArF} \cdot(R, S)-\right.\right.$} L2)]

A $0.02 \mathrm{M}$ solution of $(R, S)-\mathbf{L 2} \quad(11.6 \mathrm{mg}, 9.47 \mu \mathrm{mol})$, $\left[\mathrm{Rh}\left(\kappa^{2} \mathrm{O}, \mathrm{O}^{\prime}\right.\right.$-acac $\left.)(\mathrm{CO})_{2}\right](2.47 \mathrm{mg}, 9.47 \mu \mathrm{mol})$, and $\mathrm{KBArF}$ $(10.6 \mathrm{mg}, 12.3 \mu \mathrm{mol})$ in $\mathrm{C}_{7} \mathrm{D}_{8} / \mathrm{C}_{4} \mathrm{D}_{8} \mathrm{O}(97: 3 \mathrm{v} / \mathrm{v})$ were transferred to a $25 \mathrm{ml}$ autoclave reactor, which was pressurized to 10 bar of syngas $\left(1: 1 \mathrm{H}_{2} / \mathrm{CO}\right)$ and warmed to $40^{\circ} \mathrm{C}$. The mixture was allowed to stir for $2 \mathrm{~h}$. The reactor was cooled to room temperature and depressurized in a well-ventilated fume hood, and the reaction mixture was transferred to 5 mm HP-NMR sapphire tube. The tube was pressurized with syngas $\left(1: 1 \mathrm{H}_{2} / \mathrm{CO}\right.$, 10 bar) and the HP-NMR spectra were collected at $25{ }^{\circ} \mathrm{C}$ (see Supporting Information). MS samples were immediately recorded under $\mathrm{N}_{2}$ after depressurizing the autoclave. Spectroscopic data obtained from this solution was in agreement with the quantitative formation of the $\left[\mathrm{Rh}(\mathrm{H})(\mathrm{CO})_{2}\left(\kappa^{2} \mathrm{P}, \mathrm{P}^{\prime}-\mathrm{KBArF} \cdot(R, S)-\mathbf{L 2}\right)\right]$ complex: ${ }^{1} \mathrm{H} \quad \mathrm{NMR}$ $\left(\mathrm{C}_{7} \mathrm{D}_{8} / \mathrm{C}_{4} \mathrm{D}_{8} \mathrm{O}(97: 3 \mathrm{v} / \mathrm{v}), 500 \mathrm{MHz}\right): \delta_{7 \cdot 79}(\mathrm{~s}, 1 \mathrm{H}), 7 \cdot 77\left(\mathrm{~s},{ }_{1} \mathrm{H}\right)$, $7.66(\mathrm{~s}, 4 \mathrm{H}), 7.25(\mathrm{~s}, 1 \mathrm{H}), 7.23(\mathrm{~s}, 3 \mathrm{H}), 7.20-7.17(\mathrm{~m}, 2 \mathrm{H}), 7.15$ $(\mathrm{s}, 2 \mathrm{H}), 7.00(\mathrm{~s}, 2 \mathrm{H}), 3.94-3.92(\mathrm{~m}, 2 \mathrm{H}), 3.51-3.48(\mathrm{~m}, 2 \mathrm{H})$, 3.26-3.22 (m, 2H), 3.07-2.97 (m, $4 \mathrm{H}), 2.75-2.72(\mathrm{~m}, 2 \mathrm{H})$, 2.37-2.35 (m, $2 \mathrm{H}), 2.24-2.22(\mathrm{~m}, 2 \mathrm{H}), 2.11(\mathrm{~s}, 6 \mathrm{H}), 2.00(\mathrm{~s}, 6 \mathrm{H})$, $1.64(\mathrm{~s}, 6 \mathrm{H}), 1.63(\mathrm{~s}, 6 \mathrm{H}), 1.51(\mathrm{~s}, 18 \mathrm{H}), 1.43(\mathrm{~s}, 18 \mathrm{H}),-10.38$ (br 
$\mathrm{s}, 1 \mathrm{H}) .{ }^{13} \mathrm{C}\left\{{ }^{1} \mathrm{H}\right\} \operatorname{NMR}\left(\mathrm{C}_{7} \mathrm{D}_{8} / \mathrm{C}_{4} \mathrm{D}_{8} \mathrm{O}(97: 3 \mathrm{v} / \mathrm{v}), 125 \mathrm{MHz}\right): \delta$ 191.1, 154.0, 146.9, 144.3, 136.1, 136.1, 134.4, 133.8, 133.6, 131.5, 131.4, 131.0, 130.0, 130.0, 129.8, 126.4, 126.1, 125.8, 124.2, 123.3, 122.0, 119.6, 71.1, 70.4, 69.7, 66.6, 35.6, 34.8, 32.9, 31.1, 20.1, 20.0, 16.4, 16.3. ${ }^{31} \mathrm{P}$ NMR $\left(\mathrm{C}_{7} \mathrm{D}_{8} / \mathrm{C}_{4} \mathrm{D}_{8} \mathrm{O}(97: 3 \mathrm{v} / \mathrm{v}), 202 \mathrm{MHz}\right): \delta 143.8(\mathrm{dd}$, $\left.J_{\mathrm{RhP}}=234.4 \mathrm{~Hz} ; J_{\mathrm{PH}}=22.8 \mathrm{~Hz}\right)$. HMRS-MALDI-TOF $(\mathrm{m} / \mathrm{z})$ : $[\mathrm{M}-\mathrm{H}-\mathrm{CO}-\mathrm{K}]^{+}$calcd for $\mathrm{C}_{77} \mathrm{H}_{92} \mathrm{O}_{11} \mathrm{P}_{2} \mathrm{Rh}$, 1357.5164, found, 1357.5135. Attempts to isolate this complex in analytically pure form failed.

\section{ASSOCIATED CONTENT}

\section{Supporting Information}

The Supporting Information is available free of charge on the ACS Publications website at DOI: 10.1021/acs.joc.5bo1805. Extended tables of AHF reactions, NMR spectra, and chromatograms on chiral stationary phases (PDF).

\section{AUTHOR INFORMATION}

\section{Corresponding Author}

*E-mail: avidal@iciq.cat Phone: +34 977920210. Fax: + 34 977920228.

\section{Notes}

The authors declare no competing financial interest.

\section{ACKNOWLEDGMENTS}

The authors would like to thank MINECO (CTQ2014-60256P) and the ICIQ Foundation for financial support. Funding from the CELLEX Foundation through the CELLEX-ICIQ high-throughput experimentation platform is also gratefully acknowledged. L.R. would like to thank the ICIQ Foundation for a predoctoral fellowship. M. V. is grateful for the financial support received from the CELLEX Foundation.

\section{REFERENCES}

1) For selected reviews, see: (a) Breit, B. Angew. Chem., Int. Ed. 2005, 44, 6816-6825. (b) Breit, B.; Seiche, W. Pure Appl. Chem. 2oo6, 78, 249-256. (c) Takacs, J. M.; Chaiseeda, K.; Moteki, S. A.; Reddy, D. S.; Wu, D.; Chandra, K. Pure Appl. Chem. 20o6, 78, 501-509. (d) Breit, B. Pure Appl. Chem. 2008, 8o, 855-86o. (e) Meeuwissen, J.; Reek, J. N. H. Nat. Chem. 2o10, 2, 615-621. (f) Dydio, P.; Reek, J. N. H. Chem. Sci. 2014, 5, 2135-2145. (g) Raynal, M.; Ballester, P.; Vidal-Ferran, A.; van Leeuwen, P. W. N. M. Chem. Soc. Rev. 2014, 43, 166o-1733. (h) Raynal, M.; Ballester, P.; Vidal-Ferran, A.; van Leeuwen, P. W. N. M. Chem. Soc. Rev. 2014, 43, 1734-1787.

2) (a) Mon, I.; Jose, D. A.; Vidal-Ferran, A. Chem.-Eur. J. 2013, 19, 2720-2725. (b) Fernández-Pérez, H.; Mon, I.; Frontera, A.; Vidal Ferran, A. Tetrahedron 2015, 71, 4490-4494. (c) Vidal-Ferran, A.; Mon, I.; Bauza, A.; Frontera, A.; Rovira, L. Chem. - Eur. J. 2015, 21, 11417-11426.

3) (a) Clarke, M. L.; Fuentes, J. A. Angew. Chem. Int. Ed. 2007, 46, 930-933. (b) Li, Y.; Ma, B.; He, Y.; Zhang, F.; Fan, Q.-H. Chem. - Asian J. 2010, 5, 2454-2458. (c) van Leeuwen, P. W. N. M.; Rivillo, D.; Raynal, M.; Freixa, Z. J. Am. Chem. Soc. 2o11, 133, 18562-18565. (d) Song, F.-T.; Ouyang, G.-H.; Li, Y.; He, Y.-M.; Fan, Q.-H. Eur. J. Org. Chem. 2014, 2014, 6713-6719. (e) Ouyang, G.-H.; He, Y.-M.; Fan, Q.-H. Chem. - Eur. J. 2014, 20, 16454-16457.

4) (a) Thomas, P. J.; Axtell, A. T.; Klosin, J.; Peng, W.; Rand, C. L.; Clark, T. P.; Landis, C. R.; Abboud, K. A. Org. Lett. 2007, 9, 26652668. (b) Franke, R.; Selent, D.; Boerner, A. Chem. Rev. 2012, 112, 5675-5732.
5) (a) Diéguez, M.; Pàmies, O.; Claver, C. Chem. Commun. 2005, 1221-1223. (b) Mazuela, J.; Coll, M.; Pàmies, O.; Diéguez, M. J. Org. Chem. 2009, 74, 5440-5445.

6) Pereira, M. M.; Calvete, M. J. F.; Carrilho, R. M. B.; Abreu, A. R. Chem. Soc. Rev. 2013, 42, 6990-7027.

7) For the full set of results, the reader is referred to the Tables S1$\mathrm{S}_{5}$ in the Supporting Information.

8) See, for example: (a) Chikkali, S. H.; Bellini, R.; de Bruin, B.; van der Vlugt, J. I.; Reek, J. N. H. J. Am. Chem. Soc. 2012, 134, 6607-6616. (b) Li, S.; Wu, W.; Ji, W.; Liang, Y.; Ou, L.; Zeng, G.; Wu, W. Biol. Med. 2014, 6, 1000203/1

9) Fernández-Pérez, H.; Benet-Buchholz, J.; Vidal-Ferran, A. Org. Lett. 2013, 15, 3634-3637.

10) (a) Horiuchi, T.; Ohta, T.; Shirakawa, E.; Nozaki, K.; Takaya, H. J. Org. Chem. 1997, 62, 4285-4292. (b) Del Rio, I.; Van Leeuwen, P. W. N. M.; Claver, C. Can. J. Chem. 2oo1, 79, 560-565. (c) Mazuela, J.; Pàmies, O.; Diéguez, M.; Palais, L.; Rosset, S.; Alexakis, A. Tetrahedron: Asymmetry 2010, 21, 2153-2157. (d) McDonald, R. I.; Wong, G. W.; Neupane, R. P.; Stahl, S. S.; Landis, C. R. J. Am. Chem. Soc. 2o10, 132, 14027-14029. (e) Chikkali, S. H.; Bellini, R.; Berthon-Gelloz, G.; van der Vlugt, J. I.; de Bruin, B.; Reek, J. N. H. Chem. Commun. 2010, 46, 1244-1246. (f) Adint, T. T.; Wong, G. W.; Landis, C. R. J. Org. Chem. 2013, 78, 4231-4238. (g) Zheng, X.; Xu, K.; Zhang, X. Tetrahedron Lett. 2015, 56, 1149-1152.

11) Polo, A.; Claver, C.; Castillón, S.; Ruiz, A.; Bayón, J. C.; Real, J.; Mealli, C.; Masi, D. Organometallics 1992, 11, 3525-3533.

12) See Figure $S 1$ and Table $S 6$ in the Supporting Information for the full set of results employing syngas mixtures with different $\mathrm{H}_{2} / \mathrm{CO}$ ratios.

13) Hydrido-dicarbonyl rhodium complexes are considered the catalyst resting-states in hydroformylation reactions. See, for example: del Rio, I.; Pàmies, O.; van Leeuwen, P. W. N. M.; Claver, C. J. Organomet. Chem. 2000, 608, 115-121.

14) Small $\mathrm{P}-\mathrm{H}$ couplings indicate that the hydrido ligand has a strong preference for a cis-orientation relative to the P-ligating groups, which are coordinated in an equatorial-equatorial fashion to a trigonal-bipyramidal rhodium center. See, for example: (a) Nozaki, K.; Sakai, N.; Nanno, T.; Higashijima, T.; Mano, S.; Horiuchi, T.; Takaya, H. J. Am. Chem. Soc. 1997, 119, 4413-4423. (b) Buisman, G. J. H.; Vos, E. J.; Kamer, P. C. J.; van Leeuwen, P. W. N. M. J. Chem. Soc., Dalton Trans. 1995, 409-417.

15) Rubinshtein, M.; James, C. R.; Young, J. L.; Ma, Y. J.; Kobayashi, Y.; Gianneschi, N. C.; Yang, J. Org. Lett. 2010, 12, 3560-3563.

16) Spectroscopic data of hydroformylated products: For $\mathbf{2 a - b}$, see: (a) Zhang, X.; Cao, B.; Yan, Y.; Yu, S.; Ji, B.; Zhang, X. Chem.-Eur. J. 2010, 16, 871-877. For 2c, see: (b) Kano, T.; Mii, H.; Maruoka, K. J. Am. Chem. Soc. 2009, 131, 3450-3451. For 2d, see: (c) Friest, J. A.; Maezato, Y.; Broussy, S.; Blum, P.; Berkowitz, D. B. J. Am. Chem. Soc. 2010, 132, 5930-5931. For 2e, see: (d) Ref 1of. For 5, see: (e) Carley, S.; Brimble, M. A. Org. Lett. 2009, 11, 563-566. For 6 and 9, see: (f) ref $10 a$.

17) (a) Cobley, C. J.; Klosin, J.; Qin, C.; Whiteker, G. T. Org. Lett. 2oo4, 6, 3277-328o. (b) Cobley, C. J.; Klosin, J.; Qin, C.; Whiteker, G. T. Org. Lett. 2005, 7, 1197

18) The racemic mixture of the hydroformylated product derived from 8 was prepared using the Xantphos ligand (see Supporting Information for details). 
